\title{
Agent-based simulation modeling for regional ecological-economic systems. A case study of the Republic of Armenia*
}

\author{
L.A.Beklaryan ${ }^{1}, A . S$. Akopov $^{2}$, A.L. Beklaryan ${ }^{2}$, and A.K. Saghatelyan ${ }^{3}$ \\ beklar@cemi-rssi.ru, aakopov@hse.ru, abeklaryan@hse.ru, ecocentr@sci.am \\ ${ }^{1}$ Central Economics and Mathematics Institute of the Russian Academy of Sciences \\ 47 Nachimovski prosp., Moscow, Russia \\ ${ }^{2}$ National Research University Higher School of Economics \\ 33 Kirpichnaya st., Moscow, Russia \\ ${ }^{3}$ Center for Ecological-Noosphere Studies of the National Academy of Sciences of RA \\ 68 Abovyan st., Yerevan, Armenia
}

\begin{abstract}
Actual problems of modeling of ecologic-economic systems on the example of the Republic of Armenia (RA) are considered. Based on the methods of agent modeling and system dynamics, the simulation model of ecological-economic system which has allowed constructing the RA Ecological Map was created. The important purpose of the suggested approach is search of scenarios of rational modernization of the agent-enterprises, which are the main sources of emissions with simultaneous definition of effective strategy of the government regulation. The bi-criterial optimization problem for the ecological-economic system of RA is formulated and solved with the help of the developed genetic algorithm.
\end{abstract}

Keywords: ecological-economic system; simulation modeling; system dynamics; agent-based modeling; multiobjective optimization

DOI: $10.21469 / 22233792.2 .1 .08$

\section{Introduction}

At the present time, important direction in the field of sustainable development of ecologicaleconomic systems, which is known as "Ecological economics" [1], is developing significantly.

The main feature of this direction is studying of long-term dynamics of the ecologicaleconomic system, taking into account interaction of key economic agents: the production and refining enterprises being the main sources of emissions; consumers (both internal, and external), the government, which is carrying out the regulating functions, in particular, regarding the enterprises - main sources of emissions; vehicles and green companies, which are carrying out pure ecological products, human resources, people and environment, including minerals, water resources, power sources, land, forest, etc.

Complexity of seeking the best scenarios of long-term development of ecological-economic system is caused by not only the large-scale of such systems and their elements, but, firstly, an availability of internal nonlinear multiple feedbacks which are both balanced and reinforcing that leads to occurrence of difficult predicted multiplicative effect. For example, restriction of mining obviously reduces the level of emissions to the atmosphere, however, also leads to decrease in cumulative profit and tax revenues in the budget of the region. On the other hand, improvement of the general ecological situation in the region attracts the development of green branches of the economy, in particular, such as tourism, sectors of high technologies, green agriculture, etc. which can substitute nonecological economy industries.

*The research was partially supported by the Russian Foundation for Basic Research (grant 15-51-05011 Arm_a). 
Therefore, for seeking scenarios of long-term development of similar complex ecologicaleconomic systems, it is necessary to use the methods of system dynamics [2] and agent-based modeling, allowing to investigate the multiplicative influence of internal feedbacks, dynamical flows of natural resources in a complex interdependence between key economic agents (in particular, between enterprises and the government) and possibilities of effective government regulation.

The idea of use of methods of system dynamics and agent-based modeling for research of ecological-economic systems is not new. In particular, possibilities of recovery of the ecologicaleconomic system of South Africa [3], potential of development of ecological agriculture of China [4], and loudspeakers of stocks of water resources of China [5], loudspeakers of hunting natural resources of South America [6], etc. were investigated.

In this article, the concept of the agent-oriented model of ecological-economic system of RA is provided. Not detailed ecological map of Armenia on which dynamics of transition of manufacturing agents from initial conditions of the main sources of emissions of harmful substances to target final state - environmentally friendly productions is visualized is constructed.

The purpose of the work consists in the system analysis of the major characteristics of ecological-economic system on the example of RA taking into account the available interrelations between key economic agents and environment and forming of strategy of government regulation for manufactures in order to motivate them to transit to environmentally friendly production.

\section{Model of ecological-economic system of the Republic of Armenia}

The common simulation model of ecological-economic system of RA is developed using the methods of system dynamics and agent-based modeling. In this model, enterprises, which are the main sources of pollution of the atmosphere, need to be modernized for minimization of emissions level of harmful substances, have been identified. Such approach has allowed estimating forecast dynamics of emissions reduction of the main harmful substances at the atmosphere, such as carbon oxides $(\mathrm{COx})$, hydrocarbons $(\mathrm{CH})$, sulfur dioxide $\left(\mathrm{SO}_{2}\right)$, flying organic substances (NMVOC), nitrogen oxides (NOx), and other substances. At the same time, there is mechanism of the government regulation of activity of enterprises by means of the penalties and subsidies directed to refusal of use of the technologies polluting environment in favor of environmentally friendly technologies. The state chart, which is the algorithm of behavior of manufacturing agents considering influence of the government regulation in the form of penalties (for exceeding of limits of emissions of harmful substances) and subsidies (at essential decrease in emissions level) is represented in Fig. 1.

In Fig. 1, it is shown that agents-enterprises can have four possible final states:

1. Not ecological manufacturing (not ecological production) - production by which the enterprise remains to be one of the main sources of emissions of harmful substances.

2. Closing of the company - complete elimination of the enterprise as a result of which the source of emissions of harmful substances is eliminated.

3. Partial modernization - the enterprise is essential (in comparison with previous, the temporary period) reduces emissions level of harmful substances.

4. Ecological manufacturing (environmentally friendly production) — production by which the enterprise stops being a source of emissions of harmful substances.

Let us provide the formal description of the main part of the developed agent-oriented model of ecological-economic system of RA relating to behavior of agents enterprises with the mechanism of the government regulation. Let us note that the model of dynamics of 


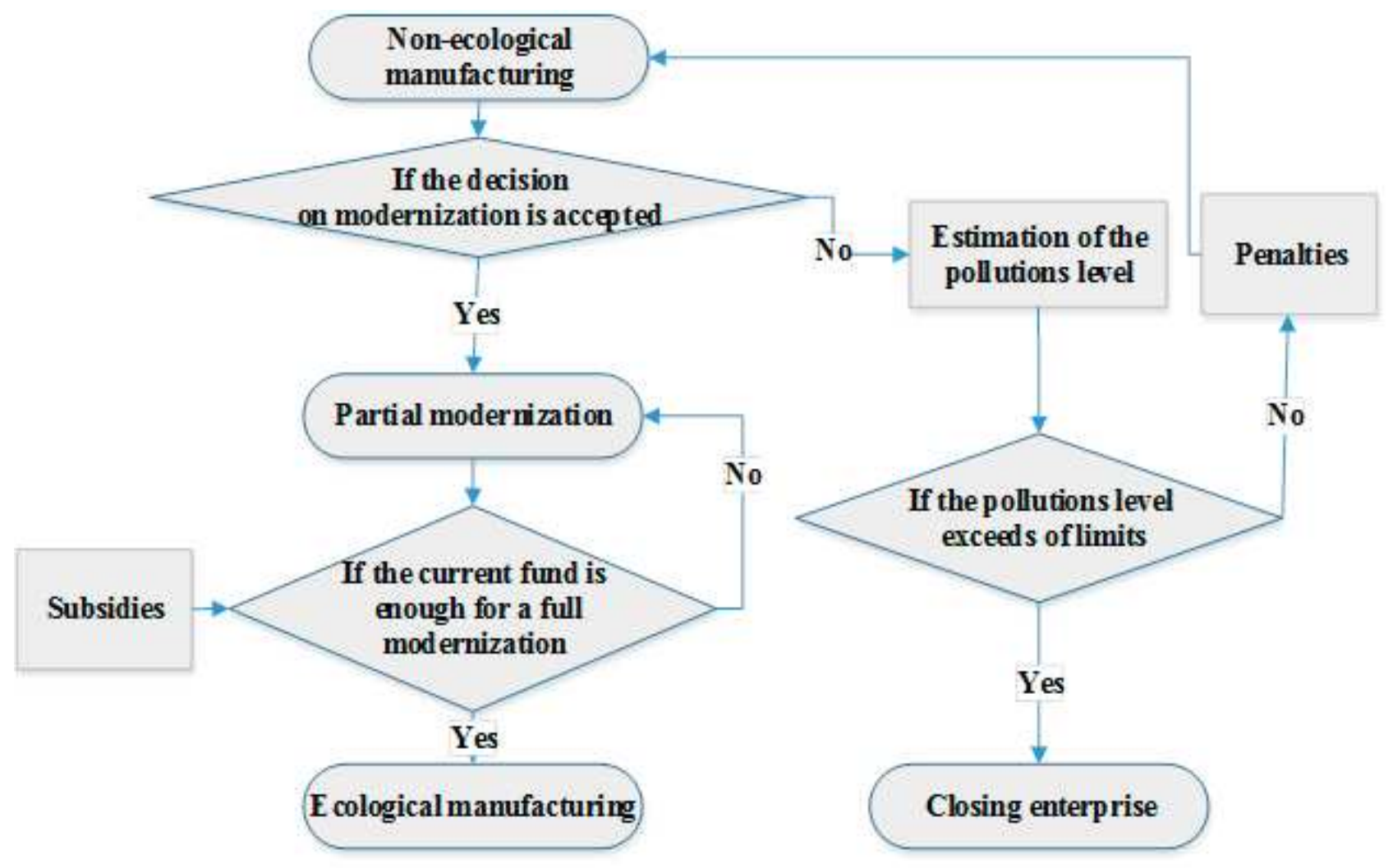

Figure 1 Algorithm of behavior of agents-enterprises

environment taking into account characteristics of all agents occupying it demands separate detailed consideration and is beyond this article.

Let us enter the following designations:

$t \in\left\{t_{0}, \ldots, t_{0}+T\right\}$ - time by years ( $t_{0}$ is the initial time moment and $T$ is the horizon of strategic planning);

$J(t)$ - set of indexes of the agents enterprises which are the sources of emissions of harmful substances; $j \in J(t)$ — index of the agent enterprise at the time moment $t ; i \in\{1, \ldots, I\}-$ kinds of harmful substances: $\mathrm{SO}_{2}, \mathrm{NOx}, \mathrm{NMVOC}, \mathrm{CH}$, etc.;

st $_{j}(t) \in\{1,2,3,4\}$ - possible states of $j$ th-agent enterprise: st $_{j}(t)=1$ - initial condition of not ecological production; $\mathrm{st}_{j}(t)=2$ - partial modernization; $\mathrm{st}_{j}(t)=3$ - environmentally friendly production; $\mathrm{st}_{j}(t)=4$ - closing the enterprise caused by the violation of the ecological legislation;

$\gamma_{j}(t)$ - the coefficient determining the volume of emissions of harmful substances in the atmosphere depending on state of $j$ th-agent enterprise:

$$
\gamma_{j}(t)=\left\{\begin{aligned}
1, & \text { if } \mathrm{st}_{j}(t)=1 \\
0.5, & \text { if } \mathrm{st}_{j}(t)=2 \\
0, & \text { if } \mathrm{st}_{j}(t)=3 \text { or st }_{j}(t)=4
\end{aligned}\right.
$$

$E_{j}(t)$ - total volume of emissions of harmful substances in the atmosphere of $j$ th-agent enterprise:

$$
E_{j}(t)=\sum_{i=1}^{I} \gamma_{j}(t) e_{i j}
$$


where $e_{i j}$ is the average volume of emissions of $i$ th-harmful substances in the atmosphere of $j$ th-agent enterprise;

$C_{j}(t)$ - costs of modernization or elimination of $j$ th-agent enterprise:

$$
C_{j}(t)=\left\{\begin{aligned}
p_{j}(t)\left(1-\gamma_{j}(t)\right), & \text { if } \mathrm{st}_{j}(t) \neq 4 \\
\bar{p}_{j}(t), & \text { if } \mathrm{st}_{j}(t)=4
\end{aligned}\right.
$$

where $p_{j}(t)$ is the modernization cost of $j$ th-agent enterprise and $\bar{p}_{j}(t)$ is the elimination cost of $j$ th-agent enterprise;

$V_{j}(t)$ - release total volume of the $j$ th-agent enterprise, it is calculated with the help of well-known production function of Kobb-Douglas:

$$
V_{j}(t)=\left\{\begin{array}{rlrl}
A_{0, j}(t)\left(L_{j}(t)\right)^{\alpha_{j}(t)}\left(K_{j}(t) \gamma_{j}(t)\right)^{\beta_{j}(t)}, & & \text { if } \mathrm{st}_{j}(t)=1 \text { or } \mathrm{st}_{j}(t)=2 ; \\
A_{0, j}(t)\left(L_{j}(t)\right)^{\alpha_{j}(t)}\left(\underline{K}_{j}(t)\right)^{\beta_{j}(t)}, & \text { if } \mathrm{st}_{j}(t)=3 ; \\
0, & \text { if } \mathrm{st}_{j}(t)=4
\end{array}\right.
$$

where $A_{0, j}(t)$ is the factor of scientific and technical progress for $j$ th-agent enterprise; $L_{j}(t)$ is the number of human resource of $j$ th-agent enterprise; $K_{j}(t)$ is the fixed assets of $j$ th-agent enterprise; $\underline{K}_{j}(t)$ is the minimum necessary fixed assets of $j$ th-agent enterprise by environmentally friendly production; $\alpha_{j}(t)$ and $\beta_{j}(t)$ are the parameters of production function of Kobb-Douglas, for which $\alpha_{j}(t)+\beta_{j}(t)=1$ for all $j \in\{1, \ldots, J(t)\}$;

$D_{j}(t)$ - grants for modernization of $j$ th-agent enterprise from the state within the suggested model are paid only to the enterprises which are already partially modernized and on condition of deficit of own means necessary for full modernization and to transition to environmentally friendly production:

$$
D_{j}(t)=\left\{\begin{aligned}
\lambda_{j}(t) C_{j}(t), & \text { if } \mathrm{st}_{j}(t-1)=2 \text { and } C_{j}(t)-P_{j}(t-1)>0 \\
0, & \text { if } \mathrm{st}_{j}(t-1) \neq 2 \text { or } C_{j}(t)-P_{j}(t-1) \leqslant 0
\end{aligned}\right.
$$

where $\lambda_{j}(t)$ is the control parameter of system of the government regulation defining share of the costs of modernization subsidized from the government $\left(0<\lambda_{j}(t) \leqslant 1\right)$;

$\bar{D}(t)$ - the maximum permissible volume of subsidies, which can be directed on modernization of all agents enterprises from the government;

$F_{j}(t)$ - penalties of $j$ th-agent enterprise from the government, caused by essential violation of the ecological legislation:

$$
F_{j}(t)=\left\{\begin{aligned}
\eta_{j}(t) P_{j}(t-1), & \text { if } E_{j}(t) \geqslant \bar{E}_{j}(t) \text { and } \mathrm{st}_{j}(t-1) \neq 3 \\
0, & \text { if } E_{j}(t) \leqslant \bar{E}_{j}(t) \text { or st }_{j}(t-1)=3
\end{aligned}\right.
$$

where $\eta_{j}(t)$ is the the control parameter of system of the government regulation defining the share of the profit got by the agent enterprise in the previous period directed on payment of penalties $\left(0<\eta_{j}(t) \leqslant 1\right)$ and $\bar{E}_{j}(t)$ is the maximum permissible level of harmful substances in the atmosphere for this enterprise; and

$P_{j}(t)$ - profit of $j$ th-agent enterprise:

$$
P_{j}(t)=\tilde{p}_{j}(t) V_{j}(t)-C_{j}(t)+D_{j}(t)-F_{j}(t)-\mathrm{Const}_{j}(t)
$$

where $\tilde{p}_{j}(t)$ is the average prices for products of $j$ th-agent enterprise and $\operatorname{Const}_{j}(t)$ is the cumulative constant expenses of $j$ th-agent enterprise (including labor costs, taxes, depreciation of fixed assets, etc.). 
Let us note that within this model, two types of agents are considered. Agents enterprises treat the first type, being the main sources of emissions of harmful substances in the atmosphere, maximizing in each time moment $t$ own profit. The government aiming at minimization of cumulative emissions level of harmful substances in the atmosphere at the expense of choice of the optimum strategy of the government regulation (differentiated in relation to agents enterprises) treats the second type. As a result, it is possible to formulate bi-criterial optimization problem for the considered ecological-economic system.

\section{Problem definition}

Problem 1. It is required to maximize profit of each $j$ th-agent enterprise under minimum possible cumulative emissions of harmful substances in the atmosphere in each time moment $t$

$$
\left\{\begin{array}{l}
\max _{\mathrm{st}_{j}(t)} P_{j}(t) \\
\min _{\lambda_{j}(t), \eta_{j}(t)} E_{j}(t)
\end{array}\right.
$$

under restrictions:

$$
\begin{gathered}
\sum_{j \in J(t)} D_{j}(t) \leqslant \bar{D}(t), \quad P_{j}(t) \geqslant 0 \\
\mathrm{st}_{j}(t) \in\{1,2,3,4\}, 0<\eta_{j}(t) \leqslant 1, j \in J(t),
\end{gathered}
$$

and other restrictions making clear economic sense.

As a result of the solution of the problems (1)-(3), the subset of optimal decisions is uniformly distributed along Pareto front. In order to get such subset with required level of a time effectivity, we applied genetic algorithms, which are similar to that described in works [7-10] and based on the class of Strength Pareto Evolutionary Algorithms (SPEA, SPEA2, etc.). The scheme of the developed genetic algorithm (GA) is presented in Fig. 2.

The developed GA is based on the classic evolution approach, which requires applying operators of selection, crossover, and mutation (see Fig. 2). The main feature of the developed GA is taking into account internal restrictions, which are implemented on the agent level. In particular, transitions from the finite states "closing of the company" and "ecological manufacturing" to other states are impossible. The transition from the state of a "partial modernization" to the state of an "ecological manufacturing" is possible only if the current fund is enough for a full modernization (when $P_{j}(t) \geqslant 0$ ).

Therefore, the GA considers only those states of agents, which are dynamical coordinated. Thus, GA touches possible trajectories of modernization of agent enterprises estimating them impact on the ecological-economic system.

It should be noted that there are some important blocks in the developed GA (see Fig. 2):

- Forming initial population of decisions for each jth-agent. As a rule, the initial state is defined as not ecological manufacturing $\left(\mathrm{st}_{j}\left(t_{0}\right)=1, j \in J\left(t_{0}\right)\right)$. However, over time, the state of agents can be changed. First of all, the GA provides forming some possible values of $\mathrm{st}_{j}(t)$ in each time moment $t \in\left\{t_{0}, \ldots, t_{0}+T\right\}$. The choice of such values can be random under restrictions;

- Loading input data to the simulation. The simulation model of the ecological-economic system was implemented in AnyLogic system. The simulation model deals with real datasets having data about characteristics of agents enterprises of RA. Therefore, the developed 


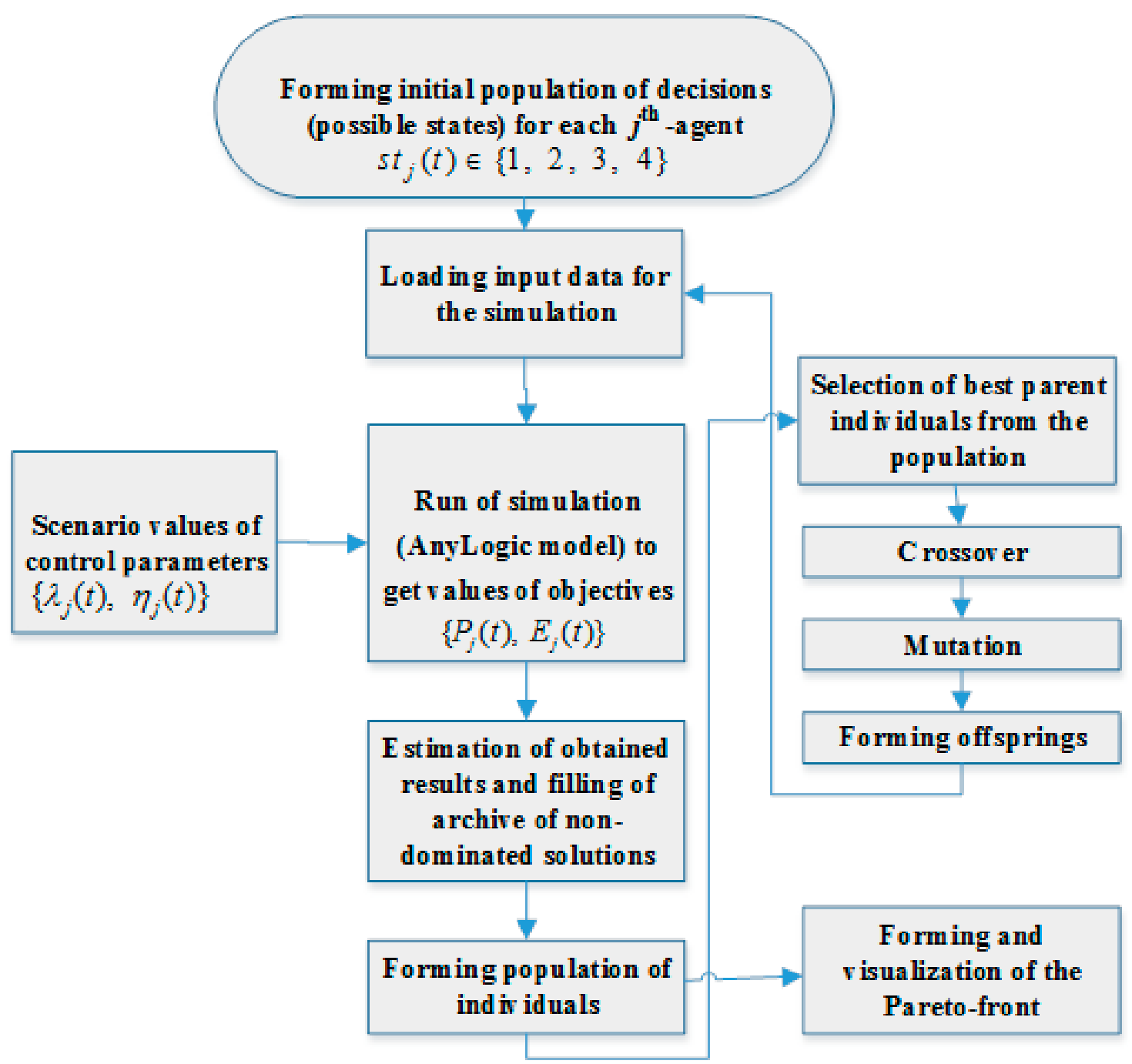

Figure 2 The scheme of the developed GA

model was integrated with the database and input data are being loaded in the model in a simulation process. Input data consist of control parameters, in particular, such as $\left\{\lambda_{j}(t), \eta_{j}(t)\right\}$ and exogenous variables such as parameters of Kobb-Duglas production function $\left\{A_{0, j}(t), \alpha_{j}(t), \beta_{j}(t)\right\}$, the predictive dynamics of resources $\left\{L_{j}(t), K_{j}(t)\right\}$, and other exogenous variables;

- Run of simulation (AnyLogic model) to get values of objectives. The simulation model is intended to obtain values of objective functions $\left\{P_{j}(t), E_{j}(t)\right\}$ under different values of control parameters;

- Estimation of obtained results and filling of archive of nondominated solutions. The filling of archive of nondominated solutions is implemented with the help of SPEA2-algorithm [8]. The algorithm is based on weighting of solutions (individuals) in proportionality to amount of its dominated solutions. Hence, individuals with smaller weights have more priority under the selection. It should be noted that such algorithm deals with convex objective functions only; 
- Forming population of individuals is based in iteration moving individuals towards the Pareto-front. For this purpose, individuals having highest Pareto ranking will be assigned larger priority to including in the population; and

- Selection of best parent individuals from the population, crossover, mutation, and forming offsprings are the standard operators of the GA.

The choice of the final scenario of modernization of the enterprises taking into account aspiration to maximizing their profit with simultaneous minimization of cumulative emissions is carried out taking into account the additional preferences created based on the analysis of possible effects of implementation of the corresponding strategy of modernization. Thus, the structure of emissions of substances in the atmosphere (on each large enterprise) and their contribution to dynamics of incidence of the population is estimated. Let us note that different chemical elements have the differentiated impact on state of health of the population. For example, excess concentration of carbon oxide (CO) leads to organism intoxication (at certain concentration, by lethal outcome), systematic sulfur dioxide emissions lead to growth of pulmonary diseases, and nitrogen oxide - to growth of respiratory diseases. Each type of diseases renders different social and economic effects, which need to be considered at decision-making, including not eco-friendly enterprises relating to closing.

\section{Simulation model of ecological-economic system}

Further on, based of the suggested algorithm of behavior of agents enterprises (see Fig. 1) taking into account dynamics of environment (see Fig. 2) and bi-criteria optimization problems (1)-(3), the simulation model of ecological-economic system implemented in AnyLogic system (Fig. 3) has been developed. Important advantages of AnyLogic system are as follows:

- possibility of the combined use of different methods of simulation modeling, in particular, system dynamics and agent-based modeling;

- ability to aggregate the simulation model with databases;
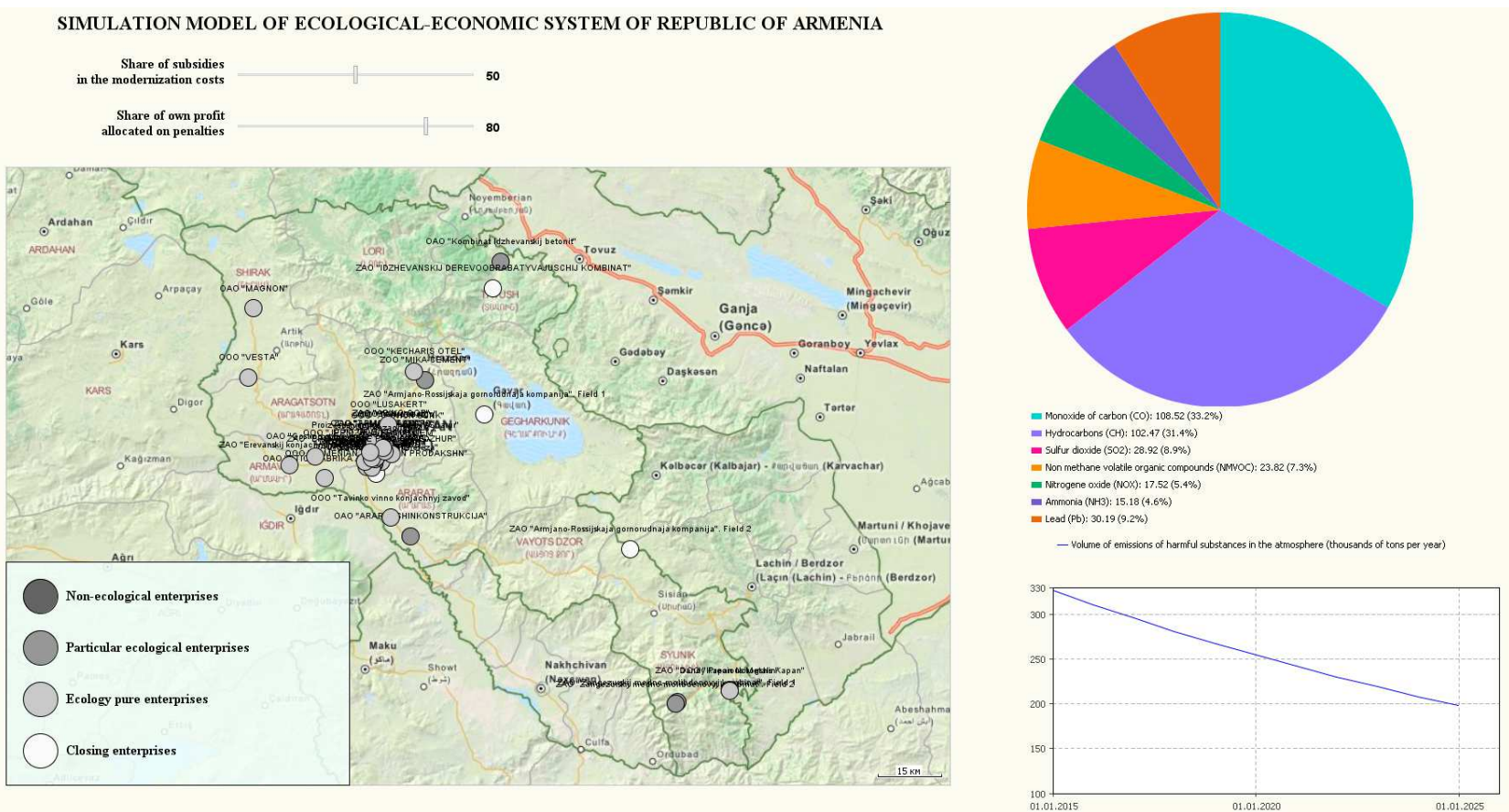

Figure 3 Simulation model of ecological-economic system of RA in AnyLogic system 
- ability to aggregate the simulation model with geographic information systems (GIS), including possibility of dynamic visualization of condition of agents on map (see Fig. 3); and

- ability to aggregate the simulation model with the developed genetic optimization algorithm, in particular, providing forming of subset of optimum decisions across Pareto for the considered problem of ecological-economic system. This algorithm is described in $[9,10]$.

Let us note that the developed simulation model is integrated with the subject-oriented database containing up-to-date information about stationary sources of emissions - the RA enterprises, created with use of statistical data of the Center for Ecological-Noosphere Studies of the National Academy of Sciences of RA provided by the Center ${ }^{1}$.

\section{Results of the simulation modeling of ecological-economic system of the Republic of Armenia}

The results of simulation modeling are unloaded in database and visualized on maps (Figs. 46). Forecast dynamics of possible states is presented on the maps (till 2025), the modernized agents enterprises being the main sources of emissions of harmful substances in RA. With black color, the enterprises which are in condition of not eco-friendly production, dark gray color - the partial modernized enterprises, light-gray color - the enterprises which have become environmentally friendly owing to full modernization, white color - the enterprises which are desirable for closing are allocated. Let us note that on the maps, not the legal but the actual addresses of the enterprises (including multiple) which are directly relating to sources of the corresponding emissions are visualized (for example, for the extracting enterprises, there are the coordinates of mining fields).

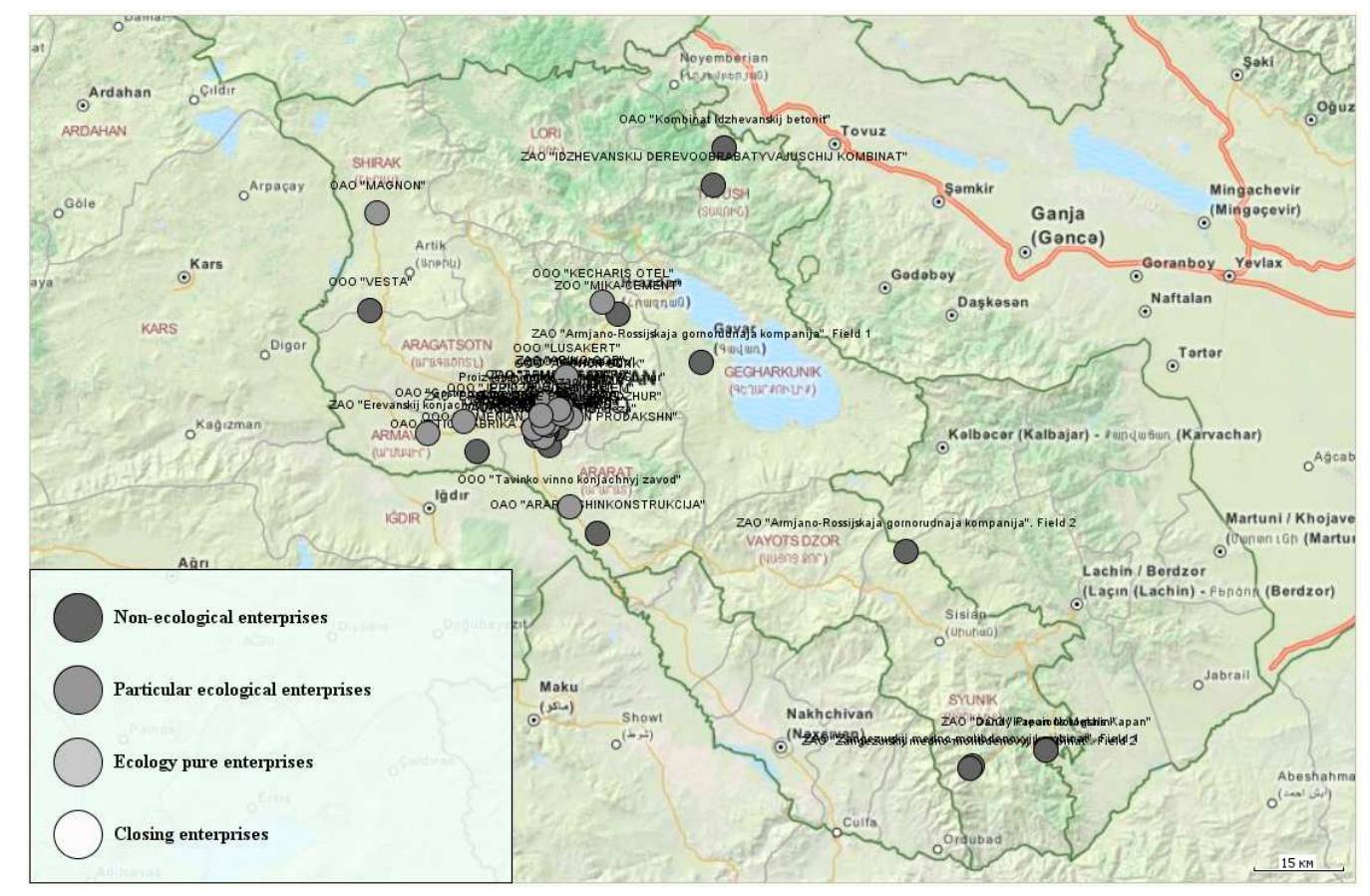

Figure 4 Initial condition of agents enterprises, being the main sources of emissions of harmful substances, visualized on the RA card for 2015

\footnotetext{
${ }^{1}$ http://ecocentre.am/.
} 


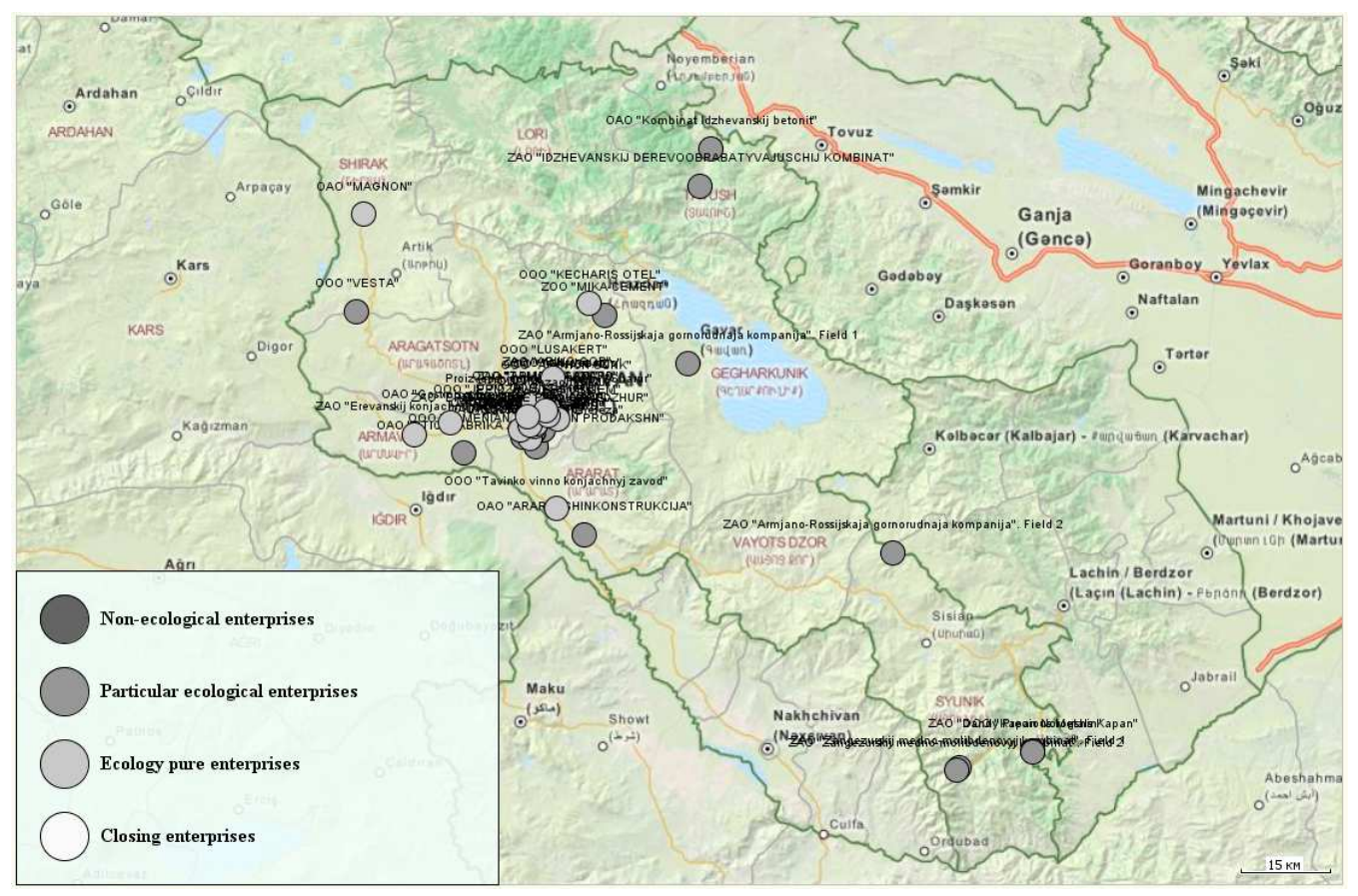

Figure 5 The intermediate condition of agents enterprises calculated by means of the developed simulation model for 2020

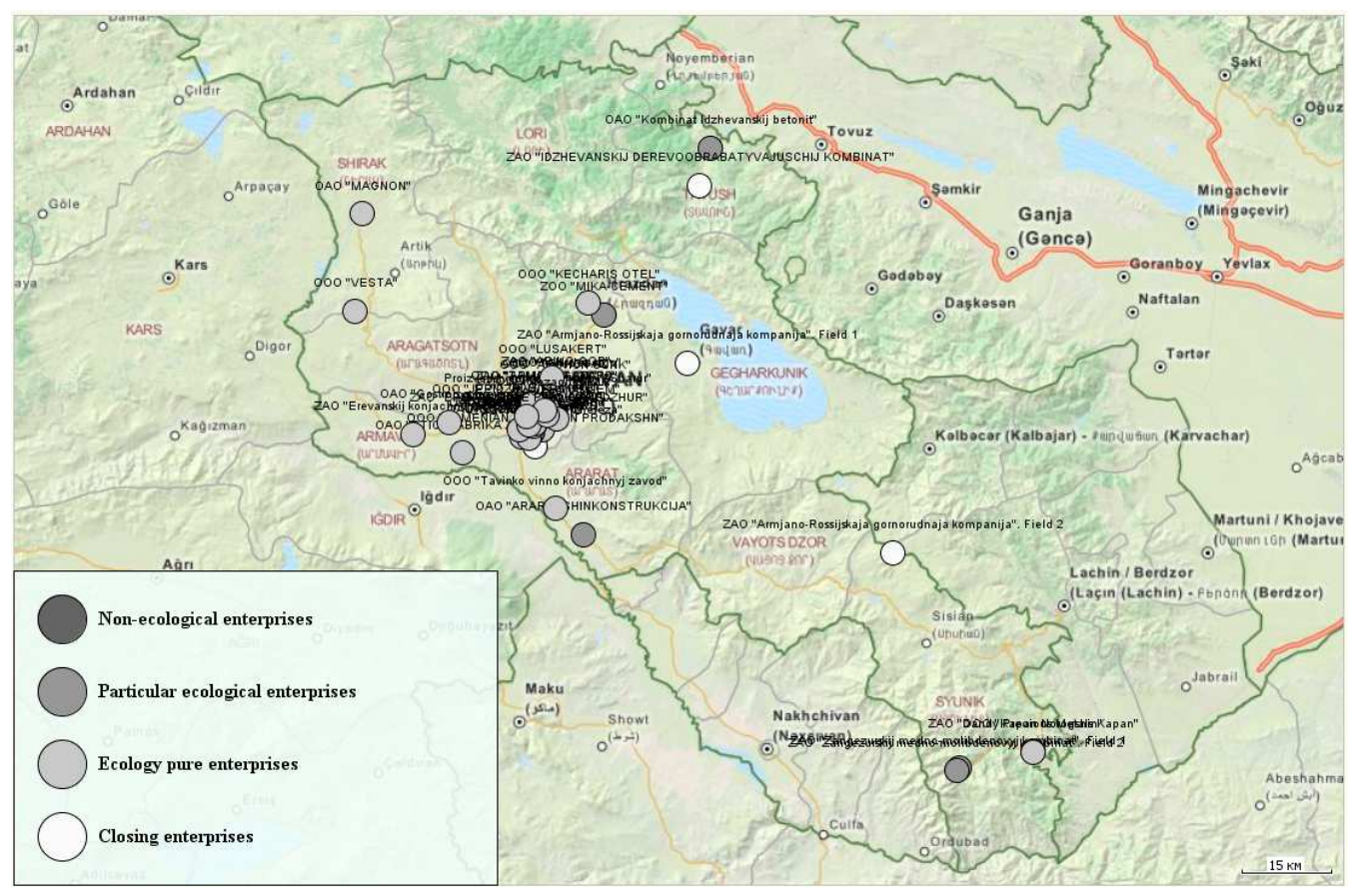

Figure 6 Optimum final condition of agents enterprises for 2025

Let us note that the developed decentralized agent-oriented model of ecological-economic systems is allowed forming the optimum plan of modernization of agent-enterprises through the scenario control of parameters of the government regulation such as penalties and subsidies. The final suggested scenario of modernization is chosen among subset of all received Pareto-optimal decisions as the most preferable to social and economic system. Thus, optimum values of parameters of the government regulation are found: $\lambda_{j}(t)$ (the share of costs of modernization 
subsidized by the government) and $\eta_{j}(t)$ (the share of profit of the enterprise received for previous year, directed on penalties) for all considered agents enterprises $j \in J(t)$. Let us note that average optimum values $\tilde{\lambda}_{j}(t) \approx 50 \%$ (for the separate enterprises of rather $10 \%$ subsidizing) and $\tilde{\eta}_{j}(t) \approx 80 \%$ (for the separate enterprises penalties have to make up to $100 \%$ of the got profit).

\section{Concluding Remarks}

The simulation model of ecological-economic system of RA considering features of system of the government ecological regulation has been developed with the help of the methods of system dynamics and agent-based modeling. The results of simulation modeling allow drawing conclusion on availability of basic possibility of modernization of the majority of the RA enterprises which activity is followed essential to emissions of harmful substances in the atmosphere. Thus, transition to model of ecological economy is possible at the expense of own means of the enterprises and subsidies from the government. Unfortunately, some enterprises, in particular, which are carrying out production and processing of copper molybdenum concentrate, cannot be given to environmentally friendly production because of the existing technology restrictions and, therefore, reasonably gradually to preserve them with simultaneous creation of new environmentally friendly productions.

\section{References}

[1] Costanza, R., J. H. Cumberland, H. Daly, R. Goodland, and R. B. Norgaard. 1997. An introduction to ecological economics. CRC Press. 275 p.

[2] Forrester, J. W. 2013. Industrial dynamics. Martino Fine Books.

[3] Crookes, D. J., J. N. Blignaut, M. de Wit, and K. J. Esler. 2013. System dynamic modeling to assess economic viability and risk trade-offs for J. Environmental Management 120:138-147. doi: http://dx.doi.org/10.1016/j.jenvman.2013.02.001.

[4] Shi, T., and R. Gill. 2005. Developing effective policies for the sustainable development of ecological agriculture in China: Case study of Jinshan County with a systems dynamics model. Ecological Economics 53(2):223-246. doi: http://dx.doi.org/10.1016/j.ecolecon.2004.08. 006.

[5] Zhang, Z., W. X. Lu, Y. Zhao, and W. B. Song. 2014. Development tendency analysis and evaluation of the water ecological carrying capacity in the siping area of Jilin Province in China based on system dynamics and analytic hierarchy process. Ecological Modelling 275:9-21. doi: http://dx.doi.org/10.1016/j.ecolmodel.2013.11.031.

[6] Iwamura, T., E. F. Lambin, K. M. Silvius, J. B. Luzar, and J. M. V. Fragoso. 2014. Agent-based modeling of hunting and subsistence agriculture on indigenous lands: Understanding interactions between social and ecological systems. Environmental Modelling Software 58:109-127. doi: http: //dx.doi.org/10.1016/j.envsoft.2014.03.008.

[7] Zitzler, E., and L. Thiele. 1999. Multiobjective evolutionary algorithms: A comparative case study and the strength Pareto approach. IEEE Trans. Evolutionary Comput. 3(4):257-271. doi: http://dx.doi.org/10.1109/4235.797969.

[8] Bleuer, S., M. Brack, L. Thiele, and E. Zitzler. 2001. Multiobjective genetic programming: Reducing bloat using spea2. Congress on Evolutionary Computation Proceedings. Seoul: IEEE. 1:536-543.

[9] Akopov, A.S., and M. A. Hevencev. 2013. A multi-agent genetic algorithm for multi-objective optimization. IEEE Conference (International) on Systems, Man and Cybernetics Proceedings. Manchester: IEEE. 1391-1395. 
[10] Akopov, A. S. 2014. Parallel genetic algorithm with fading selection. Int. J. Comput. Appl. Technol. 49(3/4):325-331. doi: http://dx.doi.org/10.1504/IJCAT.2014.062368.

Received June 15, 2016

\title{
Агентное моделирование региональной эколого-экономической системы. Тематическое исследование для Республики Армения*
}

\author{
Л. А. Бекларян ${ }^{1}$, А.С. Акопов ${ }^{2}$,А.Л. Бекларян ${ }^{2}$,А.К. Сагателян
} beklar@cemi-rssi.ru, aakopov@hse.ru, abeklaryan@hse.ru, ecocentr@sci.am

${ }^{1}$ Центральный экономико-математический институт РАН

Россия, г. Москва, Нахимовский проспект, 47

${ }^{2}$ Национальный исследовательский университет «Высшая школа экономики»

Россия, г. Москва, ул. Кирпичная, 33

${ }^{3}$ Центр эколого-ноосферных исследований Национальной академии наук Республики Армения

Армения, г. Ереван, ул. Абовяна, 68

Рассматриваются актуальные вопросы моделирования эколого-экономической системы на примере Республики Армения (РА). Основываясь на методах агентного моделирования и системной динамики, создана имитационная модель эколого-экономической системы, позволившая построить Экологическую карту РА. Важной целью предлагаемого подхода является поиск сценариев рациональной модернизации предприятий, являющихся основными источниками выбросов вредных веществ с одновременным определением эффективной стратегии государственного регулирования. Сформулирована и решена бикритериальная задача оптимизации характеристик эколого-экономической системы на примере PA.

Ключевые слова: эколого-экономическая система; имитационное моделирование; системная динамика; агентно-ориентированное моделирование; многокритериальная оптимизачия

DOI: $10.21469 / 22233792.2 .1 .08$

\section{Литература}

[1] Costanza R., Cumberland J.H., Daly H., Goodland R., Norgaard R. B. An introduction to ecological economics. - CRC Press, 1997. 275 p.

[2] Forrester J. W. Industrial dynamics. - Martino Fine Books, 2013.

[3] Crookes D. J., Blignaut J. N., de Wit M., Esler K. J. System dynamic modeling to assess economic viability and risk trade-offs for ecological restoration in south africa // J. Environmental Management, 2013. Vol. 120. P. 138-147. doi: http://dx.doi.org/10.1016/j.jenvman.2013.02.001.

[4] Shi T., Gill R. Developing effective policies for the sustainable development of ecological agriculture in China: Case study of Jinshan County with a systems dynamics model // Ecological Economics, 2005. Vol. 53. No.2. P. 223-246. doi: http://dx.doi.org/10.1016/j.ecolecon. 2004.08 .006 .

*Работа выполнена при частичной финансовой поддержке РФФИ, проект №15-51-05011 Арм_а. 
[5] Zhang Z., Lu W.X., Zhao Y., Song W.B. Development tendency analysis and evaluation of the water ecological carrying capacity in the siping area of Jilin Province in China based on system dynamics and analytic hierarchy process // Ecological Modelling, 2014. Vol. 275. P. 9-21. doi: http://dx.doi.org/10.1016/j.ecolmodel.2013.11.031.

[6] Iwamura T., Lambin E.F., Silvius K.M., Luzar J.B., Fragoso J.M. V. Agent-based modeling of hunting and subsistence agriculture on indigenous lands: Understanding interactions between social and ecological systems // Environmental Modelling Software, 2014. Vol. 58. P. 109-127. doi: http://dx.doi.org/10.1016/j.envsoft.2014.03.008.

[7] Zitzler E., Thiele L. Multiobjective evolutionary algorithms: A comparative case study and the strength Pareto approach // IEEE Trans. Evolutionary Computation, 1999. Vol. 3. No. 4. P. 257-271. doi: http://dx.doi.org/10.1109/4235.797969.

[8] Bleuer S., Brack M., Thiele L., Zitzler E. Multiobjective genetic programming: Reducing bloat using spea2 // Congress on Evolutionary Computation Proceedings. — Seoul: IEEE, 2001. Vol. 1. P. 536-543.

[9] Akopov A.S., Hevencev M. A. A multi-agent genetic algorithm for multi-objective optimization // IEEE Conference (International) on Systems, Man and Cybernetics Proceedings. - Manchester: IEEE, 2013. P. 1391-1395.

[10] Akopov A.S. Parallel genetic algorithm with fading selection // Int. J. Comput. Appl. Technol., 2014. Vol. 49. No.3/4. P. 325-331. doi: http://dx.doi.org/10.1504/IJCAT.2014.062368.

Поступила в редакиию 15.06.2016 